\title{
LIBERTAD DE INFORMACIÓN Y TRANSPARENCIA PÚBLICA BAJO EL ESTADO DE ALARMA DECRETADO PARA AFRONTAR LA PANDEMIA POR COVID-191
}

\author{
Ma Aránzazu Moretón Toquero \\ Profesora Titular de Derecho Constitucional \\ Universidad de Valladolid
}

\begin{abstract}
Cómo citar este artículo / Citation: Moretón Toquero, M.A. (2020). Libertad de información y transparencia pública bajo el estado de alarma decretado para afrontar la pandemia por Covid19. Biglino Campos, P.; Durán Alba, F. Los Efectos Horizontales de la COVID sobre el sistema constitucional, Colección Obras Colectivas, Fundación Manuel Giménez Abad, Zaragoza.
\end{abstract}

DOI: https://doi.org/10.47919/FMGA.OC20.0011

SUMARIO: I. EMERGENCIA SANITARIA, ESTADO DE ALARMA Y LIBERTAD DE INFORMACIÓN - II. LIBERTAD DE INFORMACIÓN Y DESINFORMACIÓN - 1. La libertad de comunicación durante el estado de alarma - 2. Las fuentes y la veracidad de la información - 3. "Infodemia" y desinformación, un nuevo contexto comunicativo - 4. Los medios y los profesionales de la comunicación durante el estado de alarma - III. ESTADO DE ALARMA Y TRANSPARENCIA PÚBLICA: El "cierre" del Portal de Transparencia

\section{EMERGENCIA SANITARIA, ESTADO DE ALARMA Y LIBERTAD DE INFORMACIÓN}

El recurso a la declaración del estado de alarma ha sido la herramienta jurídica que ha dado cobertura a la mayor parte de las decisiones adoptadas para tratar de hacer frente a la pandemia sanitaria por covid-19.

\footnotetext{
1 Este trabajo es resultado del proyecto de investigación del Ministerio de Ciencia, Innovación y Universidades PID2019-105334RB-I00 "Garantías frente a la desinformación en procesos electorales. Cuestiones de ciberseguridad y otros desórdenes informativos en redes" aprobado en la Convocatoria l+D+i "Retos de investigación" correspondiente a 2019.
} 
De todos es conocido que la situación que afrontamos, por muchas razones, es inédita y grave. Al desconocimiento de la enfermedad, la velocidad de propagación y sus devastadoras consecuencias se suma la magnitud global de la afectación extendida en un corto periodo de tiempo. Esta crisis sanitaria ha comprometido irremediablemente la confianza y la seguridad que habíamos construido, poniendo a prueba nuestra organización social, política y también jurídica.

El resorte jurídico con que contamos en España para afrontar los casos excepcionales, hasta ahora había tenido como único precedente la declaración de estado de alarma en el año 2010 , utilizada en un contexto bien diferente.

Para afrontar las situaciones de crisis grave, que no se pueden encarar con los mecanismos ordinarios, la propia Constitución configura un "derecho de excepción" que, a su vez, actúa como garantía del propio orden constitucional. Esta particular regulación prefigura las situaciones en que es posible activarlo, las medidas que se pueden adoptar, así como un específico sistema de control de los eventuales excesos. El art. 116 de la Constitución contiene la regulación nuclear de estos mecanismos de excepción que se complementa con lo dispuesto en otros preceptos como el art. 55.1 CE (relativo a algunos derechos fundamentales que eventualmente pueden ser suspendidos en los supuestos de declaración del estado de excepción o de sitio), el art. 117.5 CE (que remite a la ley la regulación del ejercicio de la jurisdicción militar en los supuestos de estado de sitio), y el art. 169 CE (que contiene la prohibición de iniciar la reforma constitucional durante la vigencia de alguno de los estados de emergencia).

La regulación constitucional tiene su desarrollo en la Ley Orgánica 4/1981, de 1 de junio, de los estados de alarma, excepción y sitio. Cada una de las situaciones jurídicas que refiere esta ley se define atendiendo a las contingencias excepcionales que las motivan y justifican, a las facultades extraordinarias que la Constitución y la ley confieren, así como a los particulares mecanismos de garantía previstos para mantenerlas dentro de sus justos términos. Sobre algunos de los aspectos más relevantes del derecho de excepción el Tribunal Constitucional tuvo la ocasión de pronunciarse por vez primera en la en la STC 83/2016, de 28 de abril de 2016, con ocasión de la declaración de estado de alarma, declarado mediante el Real Decreto 1673/2010, de 4 de diciembre, para la normalización del servicio público esencial del transporte aéreo. 
Ni que decir tiene que el Derecho de excepción actúa por definición como último recurso para afrontar una situación que por su exorbitancia y excepcionalidad requiere de específicas herramientas jurídicas para superar la situación de manera eficaz en beneficio del interés general. Estas medidas, por lo demás, son lógicamente limitadas y tienen vocación de transitoriedad, pues están orientadas a desplegar sus efectos en un horizonte temporal tan breve como sea posible volver a la situación de normalidad constitucional, y su vigencia no interrumpe el normal funcionamiento de los poderes constitucionales del Estado (art. 1.4 LOAES en desarrollo del art. 116.5 CE).

Los principios que informan y rigen la declaración y vigencia de cada uno de los estados de emergencia, como explicita la Ley Orgánica 4/1981, reguladora de los estados de alarma, excepción y sitio, son los de necesidad y proporcionalidad (art. 1.2); principio de temporalidad (art. 1.3); los principios de vigencia inmediata y de publicidad (art. 2); y, el principio de responsabilidad (art. 3.2) que adquiere una relevancia pareja al protagonismo que la declaración de cualquiera de estos tres estados de excepción le confiere al Gobierno.

Efectivamente, aun cuando los tres estados excepcionales son realidades cualitativamente diferenciadas, desde el punto de vista de su contenido, tienen en común que todos ellos dan cobertura jurídica a un notable incremento de los poderes del Gobierno que, a su vez, encuentran su correlato en un fuerte sistema de garantías (de orden formal y material) para la protección de la propia Constitución frente a los eventuales excesos, permaneciendo durante su vigencia el principio de responsabilidad del Gobierno (art.116.6 CE).

Las medidas que en uso de las facultades excepcionales puede adoptar el Ejecutivo, suponen una alteración del régimen jurídico-constitucional en tiempo de normalidad. Como gráficamente señala Torres Muro (2009) hay una "Constitución suspendible" (los derechos previstos en el art. $55 \mathrm{CE}$ ) sin perjuicio de su indudable importancia, y el resto es resistente a la excepción que responde a un sistema de enumeración como principio estructural básico del derecho excepcional ${ }^{2}$.

\footnotetext{
2 Torres Muro, I., "Los estados excepcionales", en Comentarios a la Constitución española, Ma Emilia Casas Baamonde y Miguel Rodríguez Piñero Dirs., Wolters Kluwer, 2009.
} 
Los derechos fundamentales que, de ordinario, actúan como límite infranqueable al ejercicio del poder del Estado, pueden ser afectados mediante restricciones o directamente suspendidos, de forma temporal, y dentro del margen constitucional. Esta posibilidad varía en intensidad según nos encontremos, respectivamente, en un escenario de estado de alarma, excepción o sitio.

Con ocasión de la declaración del estado de alarma, a diferencia de lo que ocurre con los otros dos estados excepcionales, una interpretación contrario sensu del art. 55.1 CE proscribe la suspensión de ningún derecho fundamental. Suspensión que no impide, sin embargo, la adopción de medidas limitadores o restrictivas de su ejercicio. Por lo dicho, la determinación de lo que sea limitación o restricción y su diferenciación de la suspensión de los derechos fundamentales es una cuestión espinosa que, al mismo tiempo, resulta esencial por tratarse de elementos basilares de nuestra organización político-constitucional y porque, finalmente, si las medidas adoptadas van más allá de la limitación severa y son calificables de suspensión, el Gobierno habría excedido de lo que el estado de alarma permite.

Los derechos reconocidos en el art. 20.1, apartados a) y d) CE podrán ser suspendidos -dice el art. 55 CE- cuando se acuerde la declaración del estado de excepción o de sitio en los términos previstos en la Constitución. En este sentido, han sido polémicas algunas de las medidas adoptadas por el Gobierno en relación con las libertades de expresión y de información, libertades que además de su relevancia subjetiva poseen un indudable valor objetivo, como pilar del Estado de Derecho. La discusión en este caso, como ha ocurrido en relación con otros derechos, se ha centrado en la intensidad de la afectación de las libertades de expresión e información, es decir, en la determinación de si estamos ante una limitación jurídicamente posible, o directamente ante una suspensión del derecho que excede del marco del estado de alarma (con todo lo que eso implica en orden a los controles y la responsabilidad). La declaración del estado de alarma, como ocurre con el resto de derechos fundamentales, solo daría cobertura a la adopción de medidas que, con respeto los principios que lo informan (adecuación o idoneidad, necesidad y proporcionalidad) antes señalados, supusieran una limitación o restricción del derecho, nunca una suspensión siquiera temporal (que sí sería posible en los estados de excepción y sitio, con una justificación fáctica más intensa y un aumento de los mecanismos de control). 
De las múltiples medidas que han afectado a la libertad de expresión e información, quizá la de mayor enjundia es la relativa a la afectación del derecho de acceso a la información pública, mediante la suspensión de la actividad del Portal de Transparencia. Esta cuestión ha suscitado la polémica doctrinal acerca de la dificultosa distinción entre la limitación o restricción de derechos fundamentales (que cabe en el estado de alarma) y la suspensión solo admitida en el caso del estado de excepción. Pero más allá de esta importante cuestión, habría que hacer notar que la posibilidad de que solo algunos derechos fundamentales (los que menciona el art. 55 CE sean "suspendibles" durante el estado de alarma) no les hace de categoría inferior. En situaciones de incertidumbre, y ante una crisis sanitaria, las libertades de expresión y de información resultan más relevantes, si cabe, lo mismo que la transparencia de la actividad pública, no solo como fuente de información institucional o forma de control, como herramienta de lucha contra la emergencia sanitaria, sino además, como mecanismo de prevención de prácticas corruptas que, en situaciones convulsas encuentran un clima propicio ${ }^{3}$.

\section{LIBERTAD DE INFORMACIÓN Y DESINFORMACIÓN}

\section{La libertad de comunicación durante el estado de alarma}

Las libertades de expresión e información han tenido un evidente protagonismo durante la vigencia del estado de alarma, en buena medida por las características de la contingencia extraordinaria de la que trae causa, pero también, por la necesidad de información y, siquiera de forma colateral, como consecuencia de algunas de las medidas adoptadas para hacerle frente, especialmente el confinamiento general de la población. Esta medida de alguna manera ha actuado como crisol de las demás que se fueron adoptando, así como

\footnotetext{
${ }^{3}$ Como señala el Informe de Transparencia Internacional-España, "La crisis sanitaria global ha acentuado y propiciado un escenario idóneo también para la corrupción privada. Los gobiernos se han visto obligados a decretar la flexibilización de las normas de control en la contratación pública con los riesgos que ello conlleva, justificada sin duda por la necesidad de contratar con urgencia material sanitario. Como consecuencia de ello, se ha evidenciado la existencia de algunas conductas empresariales antiéticas; de proveedores desleales o no autorizados; de acaparamiento de mercancías críticas; de suministros defectuosos y de incremento de los precios de venta al público del material sanitario de primera necesidad, entre tantas otras. Esta situación no solo resulta en perjuicio de los recursos del Estado y de los ciudadanos, sino que implica también conductas lesivas de la competencia empresarial leal y de una manifiesta falta de integridad en el sector privado". Vid. Informe de Transparency International-España "Transparencia y publicidad activa: Covid-19, p. 4.
} 
del devenir de los acontecimientos, y configuraron un paradójico escenario en que la información resultaba vital (en el más amplio sentido de la palabra) pero, al mismo tiempo, la desinformación se extendió de forma desmesurada.

Al mismo tiempo que el papel de los medios de comunicación adquiría más relevancia, los cauces de comunicación se multiplicaron exponencialmente, sobre todo las redes sociales ${ }^{4}$. En este contexto la OMS nombró como

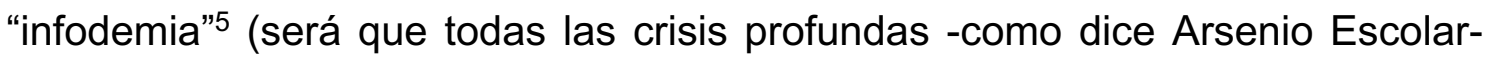
traen su propio léxico) la "sobreabundancia de información, en línea o en otros formatos", pero también "los intentos deliberados por difundir información errónea para socavar la respuesta de salud pública y promover otros intereses de determinados grupos o personas". A pesar de lo desafortunado de la denominación (y que a juicio de muchos profesionales que no ven en ella un gesto inocente, sino que se sienten estigmatizados como "agentes infodémicos") ${ }^{6}$ esta sí que describe dos hechos incontestables: la centralización del foco informativo y la sobreexposición informativa por un lado, y la generación de bulos a gran escala, por otro.

En relación con el foco informativo, hay que hacer notar que el estado de alarma se declaró para hacer frente a una emergencia sanitaria (y no de orden político, situaciones para las que también está previsto el derecho de excepción) y en este hecho encuentra su fundamento y justificación. Por esta razón, el "foco informativo" tuvo una doble (y casi exclusiva) dirección: sanitaria y política. En

\footnotetext{
${ }^{4}$ Según el estudio Digital News Report 2020 (Reuters Institute, Universidad de Oxford) WhatsApp experimentó el mayor incremento: alrededor de diez puntos porcentuales en algunos países. Más de la mitad de las personas encuestadas (51\%) utilizó algún tipo de grupo online -abierto o cerrado- para conectarse, compartir información o participar en una red local de ayuda.

${ }^{5}$ El término "infodemia" ha sido empleado y definido por la OMS como una cantidad desmesurada de información sobre un problema, que dificulta la búsqueda de una solución. Puede consistir en la difusión de información errónea, desinformación o propagación de rumores durante una situación de emergencia sanitaria.

https://www.who.int/docs/default-source/coronaviruse/situation-reports/20200305-sitrep-45-

covid-19.pdf?sfvrsn=ed2ba78b_4

También se ha hecho notar que "infodemia", lo mismo que "infoxicación", son neologismos muy expresivos para describir la realidad informativa, pero no siempre, como han denunciado algunos profesionales de la información, se utilizan de una manera neutral, pues consideran que en ocasiones se utiliza para denostar la labor de los periodistas y los medios de comunicación en interés propio.

6 "La infodemia no es un concepto inocente ni un recurso dialéctico imaginativo. Es un estigma, un reproche, una reprobación, otra más, de los poderes más ávidos de dominación surgidos del populismo, de los "hiper-liderazgos" que descreen de la madre de todas las libertades, que es la de expresión", cfr. Zarzalejos, J.A., "El periodismo en tiempos de catástrofe", Cuadernos de Periodistas, $n^{\circ}$ 40, 2020.
} 
un escenario de excepcionalidad, el escrutinio de la acción pública se ve necesariamente acentuado como forma de control del aumento de las facultades del ejecutivo que la declaración del estado de alarma confiere. Por otro lado, en un contexto de crisis sanitaria, la información resulta una herramienta esencial para la lucha contra la pandemia, de la que depende la toma de decisiones individuales de autoprotección, y colectivas de protección de la salud pública. Y más que en ningún otro momento habría que referirse a la información, en su significado más estricto, como información veraz, y la claridad del mensaje, lo que exige una especial atención a la fiabilidad de las fuentes.

\section{La veracidad de la información y el papel de las fuentes}

La confianza en la información pública y en las fuentes, así como la garantía de su veracidad es una de las mejores herramientas para combatir la desinformación a la que estamos expuestos expandida principal (pero no exclusivamente) a través de bulos o fake news, sobre todo, a través de redes sociales. Así lo destaca el Informe de Transparency International-España (mayo 2020) donde señala además cómo "en democracia, tan grave y preocupante es que las instituciones públicas no sean transparentes, como la manipulación intencional de la información provocada por falta de ética e integridad"7.

Durante la vigencia del estado de alarma se tomaron algunas decisiones por parte del Ejecutivo en materia de comunicación, que han generado gran controversia, cuando no rechazo tanto en la opinión pública como en los medios de comunicación. Algunas de ellas están teniendo algún recorrido judicial, otras, fueron decisiones de política comunicativa o acontecimientos episódicos que, si en una situación ordinaria y por separado quizá no habrían merecido más que la crítica, en un contexto inédito como el vivido sí han adquirido un mayor relieve pues, en una valoración de conjunto, es posible que unas y otras medidas se hayan potenciado entre sí, creando un clima nada favorable para la libertad de comunicación ${ }^{8}$.

Es sabido que la información inexacta se difunde ampliamente y a gran velocidad (mucho más si cuenta con canales como los que la tecnología ofrece) lo que

\footnotetext{
7 Transparency International-España, Informe "Transparencia y publicidad activa: Covid-19..., op.cit.

8 Cfr. Magallón, R., "La nueva "infonormalidad": no pienses en fake news, piensa en desinformación", Cuadernos de Periodistas, n40, 2020.
} 
hace aún más difícil para el público identificar los hechos verificados y procedentes de fuentes fiables. Por otro lado, el acceso directo a espacios de información abiertos, así como la demanda de inmediatez de la información permiten la circulación de un mayor volumen de datos sin contrastar o, directamente, campañas de desinformación premeditadas.

Rafael Jorba (en un contexto particular) ha resumido de manera muy expresiva, el tránsito hacia la denominada época de la "posverdad" en la que nos encontramos: "tradicionalmente el periodismo había defendió que las ideas son libres y los hechos son sagrados. Ahora, en cambio, las redes sociales y las tertulias han convertido las opiniones en algo sagrado y los hechos en libres"'. En el panorama comunicativo se ha producido un doble trasvase tanto en el medio como en el contenido. Por un lado, el trasvase desde los medios convencionales a las redes digitales y a las plataformas y, por otro, desde la información hacia la opinión, acentuando más su estrecha relación y, por tanto, la dificultad de diferenciación entre una y otra lo que, desde el punto de vista jurídico, como es sabido, no es irrelevante.

Tratándose de información sanitaria, situada en el centro de la agenda política, evidentemente la información errónea y falsa (como señala la OMS) puede perjudicar la salud física y mental de las personas, incrementar la estigmatización y amenazar los valiosos logros conseguidos en materia de salud. La información incorrecta trunca vidas. Sin confianza y sin la información correcta y adecuada las medidas sanitarias pueden llegar a ser ineficaces ${ }^{10}$. En este contexto, las fuentes institucionales cobran una mayor relevancia, no solo por la confianza de la que gozan sino porque, particularmente en este caso, la información está focalizada en la acción de gobierno al haber reforzado su competencia y haberse reducido el interés informativo, como he señalado, prácticamente a la acción política y a la materia sanitaria. La información "de interés público" requerida en este momento procede, casi en monopolio, del poder público, por lo que su papel

\footnotetext{
${ }^{9}$ El Mundo, sábado 12 de septiembre de 2020, p. 5.

10 "Gestión de la infodemia sobre la Covid-19: Promover comportamientos saludables y mitigar los daños derivados de la información incorrecta y falsa", Declaración conjunta de la OMS, las Naciones Unidas, el UNICEF, el PNUD, la UNESCO, ONUSIDA, la UIT, la iniciativa Pulso Mundial de las Naciones Unidas y la Federación Internacional Sociedades de la Cruz Roja y de la Media Luna Roja.

Accesible en: https://www.who.int/es/news-room/detail/23-09-2020-managing-the-covid-19infodemic-promoting-healthy-behaviours-and-mitigating-the-harm-from-misinformation-anddisinformation
} 
de fuente adquiere un papel muy superior al que pueda tener en tiempo ordinario. Siendo esto así, parece adecuado impulsar deber de transparencia para generar la confianza de la ciudadanía y posibilitar la rendición de cuentas de las decisiones adoptadas durante el estado de alarma, pero también, la exigencia de un periodismo responsable que persiga la objetividad y comprometido con la verdad, diferenciando información y opinión ${ }^{11}$.

Las cuestiones más polémicas relativas a la libertad de información, algunas de ellas recogidas en el Informe de Transparencia Internacional (y sobre las cuales hace algunas recomendaciones) son, por ejemplo, la relativa las ruedas de prensa del Presidente del Gobierno, la alusión al eventual rastreo de informaciones "desestabilizadoras" en las redes sociales, el asunto de los bulos identificados como atentatorios contra la dignidad de las instituciones, o el "cierre" del Portal de Transparencia. También, la composición de Comité de Expertos asesores del Gobierno para la gestión de la pandemia, la cuestión de los criterios y toma de datos para el recuento oficial de las personas infectadas o fallecidas a causa de la covid-19, la difusión de imágenes de féretros de las personas fallecidas a causa de la enfermedad y, más recientemente, la transparencia de los elementos de las aplicaciones de rastreo (Radar-COVID) para el control de la pandemia.

Tras la declaración del estado de alarma, la aplicación de los protocolos para evitar el contagio, impedía que los periodistas pudieran estar presentes físicamente en las ruedas de la prensa del Presidente del Gobierno. Para organizar las comparecencias la Secretaría de Estado de Comunicación arbitró un sistema de selección y agrupamiento de las preguntas que debían ser enviadas previamente a la Secretaría por los distintos medios de comunicación a través de un sistema habilitado a este fin, siendo el propio Secretario de Estado quien posteriormente las formulaba al compareciente, sin posibilidad de repreguntar. Tras las primeras ruedas de prensa, los medios reclamaron el cambio de modelo para garantizar un sistema de preguntas y repreguntas en directo, sin ningún tipo de "cribado" o selección interesada. Estas quejas desembocaron en protestas de la mayor parte de los medios de comunicación, que dejaron de asistir a las ruedas de prensa, y de un importante número de

\footnotetext{
11 Transparency International-España, Informe "Transparencia y publicidad activa: Covid-19...,
} p. 3. 
profesionales que en el manifiesto de protesta "La libertad de preguntar"12 recordaban su función de control y contrapeso del poder político, así como la necesidad de contar con mecanismos como las preguntas y repreguntas tras la asistencia a las comparecencias, sin ningún tipo de filtro previo ni dificultades añadidas.

Finalmente, el modelo fue rectificado y se adoptó un sistema de ruedas de prensa mixto (en directo y por videoconferencia) hasta finales de mayo, fecha en que se retomaron las comparecencias presenciales con aforo limitado y con reserva de algunas preguntas para asistentes por videoconferencia.

Si de ordinario una buena parte de la información y la creación de opinión pública tiene lugar a través de las redes sociales, mucho más en una situación como la que hemos vivido (sobre todo en el periodo de confinamiento) donde han sido una auténtica válvula de escape. Por su importancia, la alusión al eventual rastreo por parte de las Fuerzas de Seguridad del Estado de las informaciones "desestabilizadoras" del Gobierno difundidas en las redes sociales, ha constituido otro de los más polémicos episodios en lo tocante a las libertades de expresión e información sucedidos durante la primera fase de la declaración del estado de alarma.

En este caso, el origen de la polémica se encuentra en las declaraciones efectuadas por el Jefe del Estado Mayor de la Guardia Civil en una rueda de prensa celebrada el 19 de abril, donde hacía una descripción de las medidas que se estaban llevando a cabo para investigar y neutralizar las campañas de desinformación contra la gestión del Gobierno sobre el coronavirus que, presuntamente estaban siendo promovidas por organizaciones delictivas, y estaban siendo investigadas por la Fiscalía. En la declaración pública, el alto mando hizo alusión a la monitorización de las redes que se estaba llevando a cabo para evitar el estrés social que producen estos bulos y, por otro, para minimizar el clima contrario a la gestión de crisis por parte del Gobierno.

Estas declaraciones desataron no solo la crítica política sino también de los medios de comunicación y la opinión pública, que, sobre todo en las redes sociales denunciaron la censura estatal contra los mensajes críticos con la

\footnotetext{
12 Manifiesto "La libertad de preguntar". Accesible en: https://s1.eestatic.com/2020/04/01/espana/1585683681-lalibertaddepreguntar.pdf
} 
gestión del Gobierno. Las declaraciones del General, que inicialmente fueron atribuidas a un "lapsus" y a la inexperiencia en materia de comunicación, finalmente derivaron en un comunicado donde se trataba de aclarar que "la labor de monitorización que realizan las Fuerzas y Cuerpos de Seguridad del Estado, y en las que participa la Guardia Civil, está destinada exclusivamente a detectar aquellos bulos y desinformaciones que generan un gran nivel de estrés y alarma social, especialmente en temas de salud"13. También, según publicaron los medios, en una contraorden que anulaba la remisión semanal de datos sobre actuaciones de ciberseguridad por parte de la Guardia Civil para elaborar un informe monográfico sobre este tipo de actuaciones vinculadas a la covid-19, y para el que se solicitaba (según constaba en un correo electrónico interno del 15 de abril publicado por la prensa) a las comandancias la "identificación, estudio y seguimiento de [...] campañas de desinformación", así como "bulos y fake news susceptibles de generación de estrés social y desafección a instituciones del Gobierno".

Este episodio venía precedido por el polémico Barómetro especial del CIS correspondiente al mes de abril ${ }^{14}$ y publicado el día 1 de ese mismo mes, cuya pregunta $n^{\circ} 6$ se formulaba en los siguientes términos: “ ¿Cree Ud. que en estos momentos habría que prohibir la difusión de bulos e informaciones engañosas y poco fundamentadas por las redes y los medios de comunicación social, remitiendo toda la información sobre la pandemia a fuentes oficiales, o cree que hay que mantener libertad total para la difusión de noticias e informaciones?". Si la pregunta era inquietante, mucho más una de las respuestas ofrecidas ("Cree que habría que restringir y controlar las informaciones, estableciendo sólo una fuente oficial de información") una respuesta que, por cierto, aparecía respaldada

13 Se puede consultar el reflejo de los hechos en los medios, entre otros en: https://elpais.com/espana/2020-04-19/pp-y-cs-piden-la-comparecencia-de-marlaska-por-unasdeclaraciones-de-la-guardia-civil-sobre-los-bulos.html, $\quad$ https://www.abc.es/espana/abcigobierno-desautoriza-jefe-estado-mayor-guardia-civil-sin-oposicion-crea-version202004192121_noticia.html

${ }^{14}$ Centro de Investigaciones Sociológicas (CIS): Barómetro de abril 2020, número 3279, 1 de abril de 2020.2 Accesible en: http://www.cis.es/cis/opencm/ES/1_encuestas/estudios/ver.jsp?estudio=14505 
por un $66,7 \%$ de los encuestados frente a un $30,8 \%$ que se manifestó en contra de dicho control ${ }^{15}$.

Otro fenómeno preocupante ha sido la difusión masiva de bulos y noticias falsas en las redes sociales. Algunos de esos bulos fueron objeto de denuncia ante la Fiscalía por el grupo parlamentario Podemos, como el relativo a la difusión de una fotografía en la que aparecían decenas de ataúdes bajo las siglas PSOE y una referencia gráfica al coronavirus, con la leyenda "la foto por la que están investigando a decenas de policías y sanitarios". Dicha fotografía se demostró que fue tomada en una tragedia ocurrida en Lampedusa años antes. Las diligencias de investigación fueron finalmente archivadas a principio del mes de junio. En el decreto de archivo la Fiscalía entendió que los hechos denunciados se encuentran amparados por la libertad de expresión y se enmarcan dentro de la crítica política admisible cuyos contornos, recuerda, son más amplios en el ámbito político. Respecto de la falsedad contrastada de la fotografía sobre la que se construye el bulo, no se consideró que fuera un dato relevante para considerar los hechos como constitutivos de injuria pues reflejaba la realidad de la muerte en España de miles de ciudadanos como consecuencia del virus.

Otra cuestión no menor, de la que Transparency Internacional da cuenta en su Informe sobre España es la relativa al sistema (los sistemas) de recuento de fallecidos y la recogida de datos en las diferentes Comunidades Autónomas, una cuestión todavía no resuelta que ha generado gran desconfianza entre la ciudadanía y ha venido siendo objeto de permanente discusión. Ello a pesar de la importancia que para la ciudadanía tiene conocer de manera fiable la magnitud del problema, como primer paso para hacerle frente. Como se señala en el Informe, durante el estado de alarma, el Ministerio de Sanidad ha venido publicando diariamente los datos del avance de la covid-1 $19^{16}$ en España pero,

\footnotetext{
${ }^{15}$ Esta pregunta del CIS suscitó un comunicado de la Asociación de la Prensa de Madrid (APM): "La Asociación de la Prensa de Madrid rechaza categóricamente que los bulos se atajen limitando la libertad de información". En el comunicado se destaca que la formulación de la pregunta en esos términos pude ser interpretada como un "globo sonda" sobre una posible restricción del derecho a la información, consagrado en la Constitución, y de imponer la censura. Además, señala, la experiencia indica que el control gubernamental de la información genera muchos más rumores y bulos que la información libre y plural.

Accesible en: https://www.apmadrid.es/comunicado/la-asociacion-de-la-prensa-de-madridrechaza-categoricamente-que-los-bulos-se-atajen-limitando-la-libertad-de-informacion/

${ }^{16}$ Los datos se ofrecen agrupados en categorías: "Casos confirmados en España/ Casos en las últimas 24 horas/

Recuperados/ Fallecidos". Cfr. Transparency International-España, Informe "Transparencia y publicidad activa: Covid-19..., op. cit., p. 6.
} 
sin embargo, no se especifica cuál es la fuente ni la forma de obtención de los datos, ni la metodología utilizada para su análisis y procesamiento. Además, se plasma en el Informe, la metodología utilizada para la recogida de información ha ido cambiando, lo que ha generado cierta variación en los datos.

Es evidente que la trazabilidad del método para la obtención de los datos resulta indispensable y una exigencia básica para favorecer la necesaria confianza de la sociedad en su conjunto. Tampoco se puede obviar el efecto que tiene hacia el exterior, pues afecta a los datos que se trasladan a la UE y a los organismos internacionales. La diversidad de la metodología utilizada para la obtención de los diferentes datos relevantes, señala el Informe, exige detallar de manera clara y específica la metodología que se está utilizando para el análisis de los datos vinculados a la covid-19 en España, y para ello recomienda especificar la capacidad de testeo que tienen el Estado y las Comunidades Autónomas para contextualizar adecuadamente los datos en relación con la población y, en segundo lugar, explicar y detallar de manera más exhaustiva los datos y el avance de la covid-19. En el Informe se hace constar la necesidad de una fuente oficial fiable que garantice que "la información pública esté disponible en tiempo real y de que esté contrastada, jerarquizada y evaluada para que la ciudadanía y los distintos grupos de interés puedan acceder de forma sencilla y clara a su contenido".

La cuestión de la composición y la identificación de los integrantes del denominado "comité de expertos" que según refería el Gobierno, tenía encomendado el asesoramiento en la toma de las decisiones sobre el progreso en las fases de las diferentes provincias en el "plan de desescalada" ha sido otro de los episodios más contestados. La negativa reiterada a hacer pública esta información fue objeto de queja ante el Defensor del Pueblo alegando incumplimiento por parte del CCAES (Centro de Coordinación de Alertas y Emergencias Sanitarias) y el Ministerio de Sanidad, de las obligaciones de transparencia activa del art. 6.1 LAITPBG (que regula las obligaciones de publicidad activa de la Administración) así como del art. 11 de la Ley General de Salud Pública, que exige "transparencia e imparcialidad a las organizaciones científicas y profesionales y a las personas expertas con quienes colaboren en las actuaciones de salud pública, incluidas las de formación e investigación..." y determina que será pública, entre otros extremos, "la composición de los comités o grupos que evalúen acciones o realicen recomendaciones de salud pública...". 
Tratándose de un presunto incumplimiento del deber de transparencia, el Defensor del Pueblo elevó consulta al Consejo de Transparencia y Buen Gobierno que declaró que dicha obligación de publicidad no tenía encaje en al art. 6.1 LAITPBG porque este precepto afecta al organigrama de la estructura organizativa de los sujetos incluidos en su ámbito de aplicación, pero en la medida en que el comité no estaba formalmente creado (y por tanto no está incluido en la estructura administrativa) no se encontraba sujeto a esta obligación. Sobre la vulneración del art. 11 de la LGSP, el Consejo trasladó la consulta al Ministerio de Sanidad para la emisión de informe, donde finalmente se reconoció la inexistencia de dicho comité y que las decisiones de progreso en la desescalada eran tomadas por un grupo de expertos ad hoc formado por técnicos, profesionales y funcionarios del CCAES, encuadrado en la Dirección General de Salud Pública.

Que la Ley de Transparencia no sea de aplicación en lo relativo a las obligaciones de publicidad activa no resta carácter público a esta información ni exime de su publicación (a la que obliga la Ley General de Salud Pública) tratándose, además, de una información relevante, garantía de imparcialidad, y no constando razones de peso suficiente previstas en la Ley para retrasar o evitar dicha publicidad, en primer lugar, a iniciativa pública, pero también, a través del derecho de acceso ${ }^{17}$.

\section{3. "Infodemia" y desinformación, un nuevo contexto comunicativo}

Una de las brechas más importantes en la lucha contra la pandemia ha sido la proliferación de noticias falsas que, si bien en un contexto ordinario ha merecido atención, mucho más en este, no solo por las potenciales consecuencias dañinas sino por su magnitud, atendiendo a su gravedad y extensión. En este caso, la célebre cita "Cuando se declara la guerra, la verdad es la primera víctima" viene particularmente al caso en la lucha contra la pandemia sanitaria. A pesar de que

\footnotetext{
17 En esta línea, el Informe de Transparency International-España va más allá y recomienda "publicar de forma clara la composición y designación de los miembros de dichos comités, brindando, al menos, los siguientes datos: 1 . Nombre y apellido de la persona experta miembro del Comité, 2. Cualificación a través de la publicación de los respectivos CV y/o trayectoria profesional, 3. Tipo de contratación o especificar si es una contribución pro bono de la persona experta, 4. Agenda de las reuniones mantenidas con los siguientes datos: día, fecha, duración de la reunión y participantes de la reunión". Cfr. p. 8.
} 
la "desinformación" no es un fenómeno novedoso y reciente, sí su intensidad que ha nominado el modelo de "posverdad"18 en el que nos encontramos inmersos.

La desinformación se había identificado como una de las herramientas de desestabilización más importantes, tanto en el ámbito interno como externo. Este hecho había motivado algunas actuaciones concretas en el ámbito de la Unión Europea que, aunque ya contaba con alguna normativa para hacer frente a la desinformación, dio un paso más estructurando su respuesta en el "Plan de Acción contra la desinformación"19 (2018) un plan de actuación que, operando en diversos ámbitos, trata de evitar la desinformación y su impacto sobre los procesos democráticos y los debates sociales, que prevé la adopción de un "Código de buenas prácticas de la Unión en materia de desinformación"20 suscrito por las principales plataformas (como son Google, Facebook y Twitter),que es objeto de seguimiento periódico de su puesta en práctica.

El Plan trata de dar una respuesta coordinada a la desinformación, sustentada en cuatro pilares básicos: 1) aumento de recursos para frenar la desinformación y mejorar las capacidades de la UE para detectarla, analizarla y desenmascararla; 2) respuestas coordinadas a través de infraestructuras tecnológicas, estableciendo el Rapid Alert System (RAS) entre instituciones de la UE y Estados miembros para facilitar el intercambio de información; 3) cumplimiento del Código de buenas prácticas por parte de las plataformas en línea, movilizar al sector privado en su implicación en la lucha contra la desinformación y cooperar con las regulaciones audiovisuales nacionales y los fact-check independientes ${ }^{21}$.

La preocupación esencial es que todas estas medidas deben ser llevadas a cabo sin afectación de los valores europeos y derechos fundamentales recogidos en la Carta de Derechos Fundamentales de la UE (2000/C 364/01) ${ }^{22}$ como son la libertad de expresión (que excluye la censura), la seguridad digital, la privacidad y la libertad del público para estar informado. Otro problema no menor es quién

${ }^{18}$ La RAE define el término como "Distorsión deliberada de una realidad, que manipula creencias y emociones con el fin de influir en la opinión pública y en actitudes sociales."

${ }^{19}$ Action Plan against Disinformation (5 de diciembre de 2018).

Accesible en: https://eeas.europa.eu/sites/eeas/files/action_plan_against_disinformation.pdf

${ }^{20}$ Accesible en: https://ec.europa.eu/digital-single-market/en/news/code-practice-disinformation

${ }^{21}$ Sobre estos aspectos es clarificador el trabajo de Raquel SEIJAS: "Las soluciones europeas a la desinformación y su riesgo de impacto en los derechos fundamentales", en IDP (Revista de Internet, derecho y política) N. ${ }^{\circ} 31$ (2020).

${ }^{22}$ Accesible en: https://www.europarl.europa.eu/charter/pdf/text_es.pdf 
se erige en verificador de la verdad o falsedad de las informaciones y su independencia.

Siendo esto así, la pandemia global y paradójicamente, algunas medidas adoptadas para hacerle frente como el confinamiento de la población, han constituido un caldo de cultivo perfecto para multiplicar los efectos perniciosos de la desinformación como son la desestabilización política y la desinformación sanitaria.

El estudio de esta cuestión requeriría un análisis más profundo que excede del cometido de este trabajo donde sí creo necesario recoger algunas de las cuestiones más relevantes que se vienen planteando en los ámbitos político y sanitario.

Desde el primer punto de vista, la Comunicación conjunta de la Comisión europea al resto de instituciones de la Unión "La lucha contra la desinformación acerca de la covid-19: contrastando los datos" (10.6.2020 Join (2020) 8 final) ${ }^{23}$, ha puesto de manifiesto que "la pandemia de coronavirus ha ido acompañada de una enorme oleada de información falsa y engañosa, tentativas de agentes externos de influir en los debates nacionales en la UE, aprovechando el caldo de cultivo constituido por las preocupaciones más básicas de las personas y el rápido ciclo de la evolución de las noticias". Las campañas de desinformación y manipulación a gran escala, los bulos, las teorías conspiratorias y las noticias falsas contaminan el proceso de formación de la opinión pública y crean confusión y alarma. En esta línea, la UE ha actuado para dar respuesta a estas amenazas en distintos frentes como son: la ciberdelincuencia (como el ejercicio de la piratería y el phishing a través de enlaces relacionados con la covid-19 para esparcir programas maliciosos), la incitación ilegal al odio (acusaciones a grupos étnicos o religiosos concretos de la propagación de la covid-19, un preocupante aumento de contenido racista y xenófobo relacionado con la covid-19), las acciones de agentes extranjeros y terceros países, en particular Rusia y China, que han emprendido operaciones de influencia selectiva y campañas de desinformación acerca de la covid-19 en la UE, en su vecindad y a escala

${ }^{23}$ Comunicación conjunta al Parlamento Europeo, al Consejo Europeo, al Consejo, al Comité Económico y Social Europeo y al Comité de las Regiones "La lucha contra la desinformación acerca de la COVID-19: contrastando los datos" (Bruselas, 10.6.2020 JOIN (2020) 8 final). Accesible en:

https://eur-lex.europa.eu/legal-content/ES/TXT/PDF/?uri=CELEX:52020JC0008\&from=EN 
mundial, con las que pretenden minar el debate democrático y exacerbar la polarización social, mejorando con ello su propia imagen en relación con la pandemia ${ }^{24}$.

En el ámbito sanitario, como señala la Comisión, "las «infodemias» pueden entorpecer la respuesta eficaz de la sanidad pública y generar confusión y desconfianza". La desinformación, señala, puede tener graves consecuencias como son las de llevar a las personas a adoptar comportamientos de riesgo, haciendo caso omiso de las consignas sanitarias oficiales, o repercutir de forma negativa en nuestras instituciones democráticas y en nuestras sociedades, así como en nuestra situación económica y financiera. La Comisión constata que la crisis ha abierto la puerta a nuevos riesgos, como que los ciudadanos sean explotados o víctimas de prácticas delictivas, además del blanco de campañas selectivas de desinformación por parte de agentes extranjeros o nacionales que pretenden socavar nuestras democracias y la credibilidad de la UE y de las autoridades nacionales o regionales. La lucha contra el flujo de desinformación, información errónea y operaciones de influencia extranjera, de la que debe formar parte una comunicación proactiva y positiva, requiere actuar mediante los instrumentos de que dispone la UE y en colaboración con las autoridades competentes de los Estados miembros, la sociedad civil, las plataformas de redes sociales y la cooperación internacional, para aumentar la resiliencia de los ciudadanos $^{25}$. Esa labor debe realizarse sin menoscabo alguno de la libertad de expresión y otros derechos fundamentales y valores democráticos.

Esta situación compleja comprende la necesidad de hacer frente a retos como la información sanitaria engañosa cuajada de afirmaciones falsas (un contenido no necesariamente ilegal, pero que puede suponer un peligro directo para la vida y obstaculizar gravemente los esfuerzos por contener la pandemia), o las teorías de la conspiración capaces de poner en peligro la salud humana, quebrantar la cohesión de nuestras sociedades o suscitar violencia pública y generar malestar social, el fraude a los consumidores (como la venta de productos «milagrosos» con afirmaciones infundadas sobre sus propiedades saludables), entre otras.

\footnotetext{
${ }^{24}$ Cfr. Comunicación conjunta al Parlamento Europeo, al Consejo Europeo..., pp. 3 y 4.

25 Para más datos sobre la respuesta de la UE a la desinformación, véase: https://ec.europa.eu/info/sites/info/files/corona_fighting_disinformation.pdf, https://eeas.europa.eu/topics/countering-disinformation_en
} 
En este contexto, señala la Comisión, una de las enseñanzas extraídas de esta crisis es la necesidad de diferenciar claramente las diversas formas de contenido falso o engañoso y de calibrar las respuestas adecuadas. Con ese fin, es importante distinguir entre los contenidos ilegales, según se definen en la legislación, y los contenidos dañosos, pero no ilegales.

También es importante determinar la presencia del ánimo de engañar, de causar un perjuicio público o de obtener beneficios económicos que convierte el contenido en desinformación y la compartición de información falsa pero de buena fe, que puede considerarse información errónea.

Entre las medidas que se prevén para combatir la desinformación en sus distinbtas modalidades se prevé: el refuerzo de la comunicación estratégica dentro y fuera de la UE, la mejora de cooperación entre las instituciones y los Estados miembros de la UE, el aumento de la transparencia de las plataformas en línea acerca de la desinformación y las operaciones de influencia, apoyo a los verificadores de datos independientes (creación de una comunidad transfronteriza y multidisciplinaria de verificadores de datos e investigadores universitarios independientes que colaborarán con las distintas partes interesadas para detectar, analizar y exponer posibles amenazas de desinformación), el refuerzo de la garantía de la libertad de expresión y del debate plural (alerta del riesgo de que algunas medidas concebidas para atajar la «infodemia» se utilicen como pretexto para socavar derechos y libertades fundamentales o se apliquen de forma abusiva y con fines políticos dentro y fuera de la Unión Europea). También, el refuerzo y la sensibilización de la ciudadanía, promoviendo la información procedente de fuentes autorizadas y basar las decisiones en las recomendaciones de los científicos y los profesionales de la salud, y profundizar la cooperación con terceros paises y organizaciones internacionales.

En esta misma línea, el Secretario General de las Naciones Unidas puso en marcha en abril de 2020 una iniciativa de comunicación con el fin de combatir la difusión de información errónea y falsa. Asimismo, las Naciones Unidas han publicado una nota orientativa para abordar y combatir el discurso de odio relacionado con la covid-19 (11 de mayo de 2020).

En la Asamblea Mundial de la Salud de mayo de 2020, los Estados Miembros de la OMS aprobaron la Resolución WHA73.1, sobre la respuesta a la covid-19. En 
la resolución se reconoce que gestionar la "infodemia" es una parte crucial del control de la pandemia de covid-1926.

\section{Los medios y los profesionales de la comunicación durante el estado de alarma}

Una cuestión a la que quizá no se ha prestado demasiada atención, a pesar de su importancia, es la manera en que el estado de alarma y, en particular, la medida de confinamiento general, ha afectado a la labor de los medios y profesionales de la información.

En primer término, los propios medios hicieron notar el agravamiento de su ya delicada situación económica a causa del desplome publicitario durante el confinamiento y el auge de las redes sociales, con la evidente y grave repercusión que esto tiene desde el punto de vista de la pluralidad informativa ${ }^{27}$. Por otro, los profesionales de la información, no solo han sufrido directamente estas restricciones, sino que, además, han visto dificultado su trabajo.

Efectivamente, más allá de los episodios antes mencionados y, a pesar de ser considerados "trabajadores esenciales" en el Anexo del Real Decreto Ley $10 / 2020^{28}$, los periodistas se vieron directamente afectados en el desarrollo de su labor por las restricciones de movilidad así como en el acceso a las fuentes. Por eso la cobertura informativa durante el periodo de confinamiento se ha

\footnotetext{
${ }^{26}$ Accesible en: https://apps.who.int/gb/ebwha/pdf files/WHA73/A73_CONF1Rev1-sp.pdf En esta misma línea, la Declaración conjunta de la OMS, las Naciones Unidas, el UNICEF, el PNUD, la UNESCO, ONUSIDA, la UIT, la iniciativa Pulso Mundial de las Naciones Unidas y la Federación Internacional Sociedades de la Cruz Roja y de la Media Luna Roja (23 de septiembre de 2020).

Accesible en: https://www.who.int/es/news-room/detail/23-09-2020-managing-the-covid-19infodemic-promoting-healthy-behaviours-and-mitigating-the-harm-from-misinformation-anddisinformation

${ }^{27}$ De Querol, R., "Los medios de comunicación piden ayuda ante el desplome publicitario para mantener el esfuerzo informativo", El País, 22 de marzo de 2020.

Accesible en: https://elpais.com/sociedad/2020-03-21/las-audiencias-de-prensa-radio-ytelevision-alcanzan-maximos-pero-su-esfuerzo-informativo-se-vuelve-insostenible.html

${ }^{28}$ El apartado 11 del Anexo del Real Decreto-ley 10/2020, de 29 de marzo por el que se regula un permiso retribuido recuperable para las personas trabajadoras por cuenta ajena que no presten servicios esenciales, con el fin de reducir la movilidad de la población en el contexto de la lucha contra la Covid-19 (BOE 87, domingo 29 de marzo de 2020) incluye: a "Las personas que trabajan en los medios de comunicación y en las agencias de noticias de titularidad pública y privada han sido consideradas como servicios esenciales".
} 
realizado, sobre todo, de forma no presencial, lo que la hace distinta de cualquier otra.

Tratando de facilitar la presencialidad y la necesaria movilidad de los profesionales, la FAPE y el Sindicato de Periodistas de Portugal hicieron una solicitud conjunta para modificar el convenio bilateral de cooperación firmado por ambos países con motivo de la pandemia. La modificación pretendía que los periodistas de ambos países pudieran cubrir la información sobre la pandemia en un lado y otro de la frontera, sujetos obviamente a todas las normas de seguridad decretadas. Esta solicitud de hizo después de que el 7 de mayo, a un equipo de la agencia de noticias portuguesa Lusa, debidamente acreditado, le fuera impedido el acceso a España para realizar una información sobre el impacto del coronavirus en el trabajo transfronterizo, y ello, pese a que como he señalado, la tarea informativa estuviera contemplada dentro de las actividades esenciales.

\section{ESTADO DE ALARMA Y TRANSPARENCIA PÚBLICA: El "cierre" del Portal de Transparencia}

Una de las medidas extraordinarias de mayor calado de entre las adoptadas en el marco del estado de alarma, es la "suspensión" de la actividad del Portal de Transparencia de la Administración General del Estado. La medida está prevista en la Disposición Adicional Tercera del Real Decreto 463/2020, de 14 de marzo, de declaración del estado de alarma, junto con otras igualmente relevantes, todas ellas amparadas en una inédita situación de emergencia sanitaria ${ }^{29}$.

La Disposición Adicional (que inicialmente constaba de 4 apartados) de forma genérica (apartado 1) se refiere a "la suspensión de términos y la interrupción de los plazos para la tramitación de los procedimientos de las entidades del sector público", con la previsión de la reanudación del cómputo en el momento de pérdida de vigencia del real decreto o, en su caso, de las prórrogas del mismo,

${ }^{29}$ Real Decreto 463/2020, de 14 de marzo, por el que se declara el estado de alarma para la gestión de la situación de crisis sanitaria ocasionada por el COVID-19 (BOE núm. 67, de 14/03/2020). 
lo que ha prolongado la medida durante más de dos meses y medio ${ }^{30}$. La suspensión del cómputo de los plazos administrativos para la tramitación de los procedimientos, tal y como aclara el apartado 2, se extendía a "todo el sector público definido en la Ley $39 / 2015$, de 1 de octubre, del Procedimiento Administrativo Común de las Administraciones Públicas".

Desde el punto de vista objetivo, el Real Decreto 463/2020 de declaración del estado de alarma, en su redacción inicial, preveía de forma imperativa que la suspensión "no afectará", decía, a "los procedimientos y resoluciones a los que hace referencia el apartado primero, cuando estos vengan referidos a situaciones estrechamente vinculadas a los hechos justificativos del estado de alarma". Pero unos pocos días después, esta previsión se vio modificada en el Real Decreto 465/2020, de 17 de marzo que, además de añadir otros dos párrafos a la Disposición Adicional tercera, modificó el apartado 4 para dejar en manos de las entidades del sector público la decisión (motivada) sobre la continuación o la suspensión de dichos procedimientos ${ }^{31}$ : "sin perjuicio de lo

${ }^{30}$ Así se hace constar en un anuncio publicado en la web del propio Portal: https://transparencia.gob.es/transparencia/transparencia_Home/index/Mas/nformacion/Noveda des-de-transparencia/LevantamientoSusplencionPlazos.html

${ }^{31}$ Real Decreto 463/2020, de 14 de marzo, por el que se declara el estado de alarma para la gestión de la situación de crisis sanitaria ocasionada por el COVID-19 "Disposición adicional tercera. Suspensión de plazos administrativos.

1. Se suspenden términos y se interrumpen los plazos para la tramitación de los procedimientos de las entidades del sector público. El cómputo de los plazos se reanudará en el momento en que pierda vigencia el presente real decreto o, en su caso, las prórrogas del mismo.

2. La suspensión de términos y la interrupción de plazos se aplicará a todo el sector público definido en la Ley 39/2015, de 1 de octubre, del Procedimiento Administrativo Común de las Administraciones Públicas.

3. No obstante lo anterior, el órgano competente podrá acordar, mediante resolución motivada, las medidas de ordenación e instrucción estrictamente necesarias para evitar perjuicios graves en los derechos e intereses del interesado en el procedimiento y siempre que este manifieste su conformidad, o cuando el interesado manifieste su conformidad con que no se suspenda el plazo. 4. La presente disposición no afectará a los procedimientos y resoluciones a los que hace referencia el apartado primero, cuando estos vengan referidos a situaciones estrechamente vinculadas a los hechos justificativos del estado de alarma."

Unos días después, el Real Decreto 465/2020, de 17 de marzo, por el que se modifica el Real Decreto 463/2020, de 14 de marzo, además de añadir otros dos párrafos a la Disposición Adicional tercera, modificó el apartado 4, que pasa a tener el siguiente contenido: "4. Sin perjuicio de lo dispuesto en los apartados anteriores, desde la entrada en vigor del presente real decreto, las entidades del sector público podrán acordar motivadamente la continuación de aquellos procedimientos administrativos que vengan referidos a situaciones estrechamente vinculadas a los hechos justificativos del estado de alarma, o que sean indispensables para la protección del interés general o para el funcionamiento básico de los servicios."

Se añaden dos párrafos nuevos a la Disposición Adicional Tercera: "5. La suspensión de los términos y la interrupción de los plazos a que se hace referencia en el apartado 1 no será de aplicación a los procedimientos administrativos en los ámbitos de la afiliación, la liquidación y la cotización de la Seguridad Social. 
dispuesto en los apartados anteriores, desde la entrada en vigor del presente real decreto, las entidades del sector público podrán acordar motivadamente la continuación de aquellos procedimientos administrativos que vengan referidos a situaciones estrechamente vinculadas a los hechos justificativos del estado de alarma, o que sean indispensables para la protección del interés general o para el funcionamiento básico de los servicios".

Los dos párrafos añadidos por el Decreto de modificación, de 17 de marzo, introdujeron sendas excepciones a la suspensión de los plazos de tramitación, que tienen que ver con el cumplimiento de obligaciones por parte de los ciudadanos: los procedimientos administrativos en los ámbitos de la afiliación, la liquidación y la cotización de la Seguridad Social, y los plazos tributarios, sujetos a normativa especial, en particular, los plazos para la presentación de declaraciones y autoliquidaciones tributarias.

El precepto comentado no recogía de forma expresa ninguna otra excepción, de manera que la suspensión de los plazos administrativos también afectaba de lleno a las solicitudes de acceso a la información pública y ello, a pesar de que el procedimiento se tramita de manera telemática ${ }^{32}$.

Esta medida, que inicialmente pasó un tanto inadvertida (quizá por la generalidad de su enunciado), fue contestada al poco tiempo por los profesionales de la información que comprobaron la paralización de sus solicitudes de acceso canalizadas a través del Portal de Transparencia (que contenía el anuncio de la medida). También, por las asociaciones en defensa de la transparencia, que de forma conjunta manifestaron reiteradamente su queja por estas medidas

6. La suspensión de los términos y la interrupción de los plazos administrativos a que se hace referencia en el apartado 1 no será de aplicación a los plazos tributarios, sujetos a normativa especial, ni afectará, en particular, a los plazos para la presentación de declaraciones y autoliquidaciones tributarias."

32 A pesar de que la implantación de la Administración electrónica es un hecho (al menos formalmente) en la mayor parte de las administraciones y que esto ha reducido notablemente la necesidad de la presencia física de los ciudadanos en las dependencias administrativas, también es cierto que el normal funcionamiento de la Administración podía verse alterado por la adopción de la medida de confinamiento si bien, este efecto se vio amortiguado por la implantación del teletrabajo. Otra cosa es si esta posibilidad de teletrabajo era real, es decir, si la Administración disponía de los medios necesarios para hacerlo efectivo.

Sobre este aspecto vid. Baño León, J. M., "Por qué debe alzarse la suspensión de plazos procesales y administrativos, aunque continúe el estado de alarma". 11 de mayo de 2020.

Accesible en: https://www.iustel.com/diario_del_derecho/noticia.asp?ref_iustel=1198066 
limitadoras de la libertad de información ${ }^{33}$. Además de la dificultad de encontrar una justificación suficiente y directa para esta restricción en la crisis sanitaria que motivó la declaración del estado de alarma, se hizo notar también la contradicción de la adopción de esta decisión en un contexto excepcional, marcado por el confinamiento general de la población, la avidez informativa y, al mismo tiempo, la proliferación de informaciones falsas, carentes de toda veracidad ${ }^{34}$. Una medida limitadora de la función informativa precisamente en un momento en que, por necesaria, resultaba imprescindible robustecerla.

La suspensión de los plazos para la tramitación de los procedimientos de acceso (y de los demás plazos administrativos) se prolongó, como he señalado, hasta el día 1 de junio. El art. 9 del Real Decreto 537/2020, de 22 de mayo, por el que se prorroga el estado de alarma, dictado ya en periodo de "desescalada", acordaba la reanudación o, en su caso, el reinicio del cómputo de los plazos que hubieran sido suspendidos, y la Disposición derogatoria única de dicha norma, dejó expresamente sin efecto la Disposición adicional tercera del Real Decreto 463/2020, de 14 de marzo.

Tras el primer mes del largo periodo de vigencia del estado de alarma, desde la Secretaría General de Función Pública (Ministerio de Política Territorial y Función Pública) se publicó una Nota informativa en relación con el funcionamiento del Portal de la Transparencia durante este tiempo ${ }^{35}$ (17 de abril

33 El 15 de abril de 2020 Transparencia Internacional (avalada por otras 80 firmas de organizaciones y sociedad civil) dirigió una "carta abierta" a los presidentes de la Comisión europea y del Consejo en la que alertan de los excesos que aprovechando la crisis sanitaria se están llevando a cabo desde la óptica de las libertades de comunicación. El documento, como muestra, se refiere de modo particular y expreso a las medidas adoptadas por el Parlamento y el Gobierno húngaro La declaración pone de manifiesto de forma general que la crisis no debe servir como cortina de humo para actividades antidemocráticas, apela a la proporcionalidad de las medidas excepcionales y a la necesidad de limitar su duración en el tiempo y señala el peligro de utilizar la situación como pretexto para desmantelar la democracia y socavar el imperio de la ley. En particular el texto se refiere a las medidas adoptadas Accesible en: https://transparency.eu/ruleoflaw-open-letter/

${ }^{34}$ La Comunicación conjunta de la Comisión al Parlamento Europeo, al Consejo Europeo, al Consejo, al Comité Económico y Social Europeo, y al Comité de las Regiones "La lucha contra la desinformación acerca de la COVID-19: contrastando los datos" (10 de junio de 2020) constata que "El confinamiento social ha obligado a millones de personas a permanecer en sus hogares y aumentado el uso de las redes sociales como medio de acceso a la información precisamente en un momento en el que las plataformas en línea, los verificadores de datos y los usuarios de las redes sociales están notificando millones de publicaciones falsas o engañosas" (https://ec.europa.eu/info/sites/info/files/corona_fighting_disinformation.pdf).

Accesible en: https://eur-lex.europa.eu/legal-content/ES/TXT/?uri=CELEX:52020JC0008

${ }_{35}$ Accesible en: https://transparencia.gob.es/transparencia/dam/jcr:f3abf704-ff10-4dbd-b80abe6bf36a22d5/Nota\%20informativa\%20funcionamiento\%20del\%20Portal\%20Transparencia.pdf 
de 2020). Dicha nota despejó algunas de las dudas planteadas acerca de si la suspensión afectaba a la tramitación de las solicitudes de acceso, y confirmó algunas sospechas. Efectivamente, como de manera expresiva se preguntaba M. A. Blanes: “¿cómo van a desarrollar su trabajo los periodistas si se considera que los plazos de tramitación de las solicitudes del derecho de acceso a la información pública están suspendidos durante el estado de alarma? No tienen ningún sentido. Lo lógico sería al revés. No solo que no estuvieran suspendidos, sino que los plazos se hubieran acortado por razones de urgencia"36.

El contenido de la Nota se refiere sobre todo a las obligaciones de transparencia activa, sobre las que textualmente señala que "el Portal de la Transparencia de la Administración General del Estado está funcionando con normalidad en lo referente a la publicidad activa, publicando la información legalmente exigida".

Formalmente no se puede hablar de "cierre del Portal de Transparencia" (como titulaban algunos medios de comunicación) porque, efectivamente, el Portal no se vació de contenido y ha conservado la información ya publicada cumpliendo las obligaciones básicas de publicidad activa, y ofrecía información sobre el estado de alarma en un apartado específico que a su vez permitía dirigirse a la página del Punto de Acceso General y de las Medidas tomadas por el Ministerio de Sanidad ${ }^{37}$. Ahora bien, en la práctica si no podría calificarse como "funcionamiento normal" (en expresión de la Nota) en una situación ordinaria, mucho menos en un periodo excepcional como el que hemos vivido en el que, por esta razón, la información cobró una especial importancia.

Por un lado, el Portal al parecer no recogía ni actualizaba ${ }^{38}$ toda la información que debería ser publicada de conformidad con lo que exige la Ley de Transparencia (como, por ejemplo, los contratos adjudicados -también los de urgencia- con motivo de la covid-19 por los distintos Ministerios, en particular, por el de Sanidad para el aprovisionamiento de material sanitario, una cuestión

\footnotetext{
${ }^{36}$ Blanes Climent, M.A., "El derecho de acceso a la información pública sobre el coronavirus durante el estado de alarma". Accesible en: https://miguelangelblanes.com/2020/03/31/elderecho-de-acceso-a-la-informacion-publica-sobre-el-coronavirus-durante-el-estado-de-alarma/ 37 Estos hechos han sido recogidos y valorados positivamente en el citado Informe de Transparency International-España "Transparencia y publicidad activa: Covid-19 y estado de alarma en España. Recomendaciones para la transparencia y prevención de la corrupción en el sector público y privado" (mayo 2020).

${ }^{38}$ Art. 5.1 LTAIPBG: "1. Los sujetos enumerados en el artículo 2.1 publicarán de forma periódica y actualizada la información cuyo conocimiento sea relevante para garantizar la transparencia de su actividad relacionada con el funcionamiento y control de la actuación pública."
} 
que generó polémica por su evidente alto interés) ${ }^{39}$. Por otro lado, tampoco el Portal estuvo operativo durante el periodo indicado en lo que al derecho de acceso a la información púbica se refiere, suspendiendo con ello, de facto, el ejercicio de este derecho ${ }^{40}$. Y ello cuando precisamente, el derecho de acceso es el cauce más potente para cumplir con el deber público de transparencia informativa y con el derecho a la información de los ciudadanos. Aún más en una situación de declaración de estado de alarma donde es necesario un mayor control o contrapeso.

Por mucho que (como reconoce la Nota en su apartado 5) se tratase de una suspensión temporal o que las unidades de transparencia estuvieran "trabajando de manera activa en la tramitación interna de las solicitudes ${ }^{41}$ para evitar que se produjera acumulación y estar en disposición de responder lo antes posible", lo cierto es que el suministro de información (y la posibilidad de recurso) se demoró

${ }^{39}$ Como señala Blanes Climent, el artículo 8.1.a) de la Ley 19/2013, de 9 de diciembre, de Transparencia, Acceso a la Información Pública y Buen Gobierno obliga a publicar esta información sobre los contratos, también los de emergencia. Una información, por otra parte, con relevancia sobreañadida si atendemos al contexto de grave crisis sanitaria y escasez de medios de protección.

El Informe de Transparency International-España (mayo 2020) señala con claridad cómo "la crisis sanitaria global ha acentuado y propiciado un escenario idóneo también para la corrupción privada. Los gobiernos se han visto obligados a decretar la flexibilización de las normas de control en la contratación pública con los riesgos que ello conlleva, justificada sin duda por la necesidad de contratar con urgencia material sanitario. Como consecuencia de ello, se ha evidenciado la existencia de algunas conductas empresariales antiéticas; de proveedores desleales o no autorizados; de acaparamiento de mercancías críticas; de suministros defectuosos y de incremento de los precios de venta al público del material sanitario de primera necesidad, entre tantas otras. Esta situación no solo resulta en perjuicio de los recursos del Estado y de los ciudadanos, sino que implica también conductas lesivas de la competencia empresarial leal y de una manifiesta falta de integridad en el sector privado." (p. 4).

Cfr.: Blanes Climent, M. A., "C Comentarios a la Nota del Portal de Transparencia (17/4/2020): se confirma el apagón informativo sobre el Covid-19 durante el estado de alarma". Accesible en: https://miguelangelblanes.com/2020/04/18/comentarios-a-la-nota-del-portal-de-transparencia17-4-2020-se-confirma-el-apagon-informativo-sobre-el-covid-19-durante-el-estado-de-alarma/ 40 Con claridad meridiana Mestre Delgado expresa: "Aun sin haberlo establecido de forma expresa, el Real Decreto que declaró el estado de alarma habría producido el efecto de suspender en la realidad de las cosas, y con carácter general (algunas excepciones pueden apreciarse) el derecho de acceso a la información, como consecuencia de la decisión de paralización de las actuaciones de tramitación de los procedimientos administrativos y judiciales (en el orden contencioso administrativo) ya que ni las solicitudes de acceso que se presentan en el portal de transparencia se tramitan, ni tampoco las reclamaciones que resuelve el Consejo de Transparencia ni los recursos contencioso administrativos que hubiesen sido interpuestos frente a alguna de aquellas." cfr. Mestre Delgado, J. F., "La transparencia de las Administraciones Públicas en tiempos de coronavirus (COVID19)", diario del derecho, lustel, 28 de abril 2020

${ }^{41}$ Esta referencia a que se estaba trabajando internamente parece dar a entender que no existía carencia de medios o que la falta de prespecialidad de los funcionarios no era un obstáculo. 
un largo periodo, el de estado de alarma, ocasionando, en definitiva, la suspensión del derecho.

Esta paralización no puede entenderse "subsanada", como parece que se quiere dar a entender, a través de los otros medios (directos o indirectos) de suministro de información pública sanitaria puestos a disposición de la ciudadanía, y que se mencionan en la Nota (en otras páginas web de diferentes instituciones enlazadas en el Portal, ruedas de prensa, comparecencias, etc.).

Si estos medios no se han revelado por varias razones (dispersión, accesibilidad de la información, descoordinación, diferencia de interlocutores...) como una opción satisfactoria para el cumplimiento de las obligaciones de publicidad activa que, en esta situación excepcional debe ser más intensa para evitar la proliferación de bulos, mucho menos pueden ser valorados como una alternativa al ejercicio del derecho de acceso, pues ni la información sanitaria es la única "de interés general", ni la proactividad de la Administración puede sustituir la libertad del ejercicio del derecho de acceso, que se concreta en la facultad de elegir y precisar la información que (dentro de los parámetros legales) deba ser suministrada, y donde el juicio del interés o la relevancia de la información que se solicita (que ni siquiera requiere su acreditación ni desde luego coincidir con el criterio del poder público) es facultad del propio solicitante.

Efectivamente, publicidad activa y derecho de acceso son cauces a través de los cuales el deber de transparencia de la Administración pública se hace efectivo, pero son jurídicamente realidades distintas y no necesariamente caras de la misma moneda. En otras palabras, el derecho de acceso es mero reverso de las obligaciones de publicidad activa; es un recurso mucho más amplio y potente. Y ello, a pesar de que se denomine "publicidad activa" al deber de las administraciones públicas de facilitar la información que determina la ley. Esta denominación, que es entendible en un enfoque de la transparencia desde la posición de la Administración, parece dejar en un segundo plano la posición del solicitante que, a través del derecho de acceso, es en quien reside la iniciativa para seleccionar y determinar objetivamente la información que precisa y que, dentro del margen legal, le debe ser suministrada.

En este ámbito del derecho de acceso, se pueden traer a colación varias decisiones limitadoras adoptadas en este periodo que quedan poco o nada clarificadas en la citada Nota. 
En primer lugar, la relativa a la extensión temporal de la suspensión general de los plazos administrativos, que incluye el procedimiento de acceso a la información pública ( $\mathrm{y}$ a los eventuales recursos ante el Consejo de Transparencia y Buen Gobierno) lo que, de facto, suspende el derecho mismo durante todo ese tiempo. Efectivamente, como se señala en el apartado B).1 de la nota aclaratoria, la suspensión de los plazos afecta a "todos los procesos administrativos", una mención genérica que afecta de lleno a las solicitudes de acceso a la información pública ${ }^{42}$.

Ahora bien, en la Nota se omite que la misma Disposición adicional del Decreto que declara el estado de alarma también excepciona algunas materias (entre las que no se encuentra el derecho de acceso) y que el Real Decreto que lo modifica (R.D. 465/2020, de 17 de marzo) dejaba en manos de las entidades del sector público la decisión sobre la continuación o la suspensión, una posibilidad de rectificación que no se llegó a materializar más que en contadas ocasiones (a fecha 28 de abril, Mestre Delgado en un interesante trabajo da cuenta del levantamiento de la suspensión o interrupción de los plazos en media docena de casos $)^{43}$.

La declaración del estado de alarma se lleva a efecto, como se recoge en el art. 1 del Real Decreto 463/2020 "con el fin de afrontar la situación de emergencia sanitaria provocada por el coronavirus covid-19". En la nota aclaratoria (que lo describe expresamente como "una suspensión temporal vinculada al estado de alarma") tampoco se refieren cuáles son las circunstancias derivadas de la pandemia sanitaria o de la situación excepcional que se invocan para justificar la decisión de suspender los procedimientos de acceso a la información o, para apreciar la necesidad y proporcionalidad de la medida, en definitiva, su justificación. Razones que tendrían que ser de peso ${ }^{44}$, particularmente intensas,

\footnotetext{
42 Ibáñez García, I., "La lucha por la Transparencia durante el estado de alarma", Diario La Ley, No 9639, Sección Tribuna, 25 de mayo de 2020.

${ }^{43}$ Estos casos que señala Mestre Delgado en su artículo son: los procedimientos para solicitar y conceder la gracia del indulto, procedimientos tramitados por la CNMV, procedimientos de adquisición de la nacionalidad española, procedimientos tramitados por la Agencia Estatal de Seguridad Aérea, procedimiento de convocatoria para 2020 de la concesión de las subvenciones destinadas a asociaciones, fundaciones y demás entidades sin ánimo de lucro, cuyo objeto sea la representación y defensa de las víctimas del terrorismo, y actividades de fabricación e importación de productos cosméticos. Cfr. Mestre Delgado, J. F., "La transparencia de las Administraciones Públicas en tiempos...", óp. cit.

${ }^{44}$ Desde un punto de vista práctico, también habría que contar con que en una situación excepcional como la de la pandemia se ha puesto a prueba la infradotación de medios personales y materiales de las distintas Administraciones para hacer frente a su función siquiera
} 
teniendo en cuenta no solo la relevancia del Portal de Transparencia como fuente de información pública ${ }^{45}$ sino también, atendiendo a la dimensión objetiva de las libertades de expresión e información en el sistema democrático (su contribución al debate y a la formación de la opinión pública pero también como herramienta de rendición de cuentas) y, a la intrínseca relación que el derecho de acceso guarda con ellas pero también, con el derecho de participación del art. 23 CE lo que le confiere, a juicio de un gran sector doctrinal, un rango fundamental que excluiría la posibilidad de suspensión en el marco de la declaración del estado de alarma.

Como bien dice el Preámbulo de La Ley 19/2013, de 9 de diciembre, de Transparencia, Acceso a la Información Pública y Buen Gobierno, "la transparencia, el acceso a la información pública y las normas de buen gobierno deben ser los ejes fundamentales de toda acción política"46.

limitadamente. También la relativa implantación de la Administración electrónica o las posibilidades de "teletrabajo" para garantizar su continuidad. No obstante, entiendo que este no puede ser obstáculo para decisiones generales, o soluciones drásticas basadas en la inoperancia práctica, desconociendo otro tipo de valoración.

${ }^{45}$ El Portal de la Transparencia" es la plataforma, dependiente del Ministerio de Política Territorial y Función Pública, a través de la Dirección General de Gobernanza Pública, por la que se podrá acceder a la información de la Administración General del Estado prevista en la Ley, cuyo conocimiento sea relevante para garantizar la transparencia de su actividad relacionada con el funcionamiento y control de la actuación pública. También contendrá la información que los ciudadanos soliciten con mayor frecuencia en ejercicio del derecho de acceso a la información pública y las resoluciones denegatorias del derecho de acceso, previamente anonimizadas".

En el Portal publican su información: la Administración General del Estado, las entidades gestoras y los servicios comunes de la Seguridad Social así como las mutuas colaboradoras de la Seguridad Social, los organismos autónomos, las Agencias Estatales, las entidades públicas empresariales y las entidades de Derecho Público que, con independencia funcional o con una especial autonomía reconocida por la Ley, tienen atribuidas funciones de regulación 0 supervisión de carácter externo sobre un determinado sector o actividad; y las entidades de Derecho Público con personalidad jurídica propia, vinculadas a cualquiera de las Administraciones Públicas o dependientes de ellas, incluidas las Universidades públicas."

Accesible en: https://transparencia.gob.es/transparencia/transparencia_Home/index/Derechode-acceso-a-la-informacion-publica/Guia-del-ciudadano.html

46 Como dice el Preámbulo de la Ley de Transparencia, "Sólo cuando la acción de los responsables públicos se somete a escrutinio, cuando los ciudadanos pueden conocer cómo se toman las decisiones que les afectan, cómo se manejan los fondos públicos o bajo qué criterios actúan nuestras instituciones podremos hablar del inicio de un proceso en el que los poderes públicos comienzan a responder a una sociedad que es crítica, exigente y que demanda participación de los poderes públicos...en estos países, los ciudadanos pueden juzgar mejor y con más criterio la capacidad de sus responsables públicos y decidir en consecuencia. Permitiendo una mejor fiscalización de la actividad pública se contribuye a la necesaria regeneración democrática, se promueve la eficiencia y eficacia del Estado y se favorece el crecimiento económico". 
El legislador español materializó el desarrollo del principio de transparencia de la actividad pública a través de un doble cauce. Por un lado, a través de la imposición de un conjunto de obligaciones a la Administración pública, que denomina publicidad activa $\mathrm{y}$, por otro, mediante el reconocimiento a los ciudadanos de un derecho de acceso la información pública, por propia iniciativa, con anclaje constitucional en el art. 105 b) CE, que reconoce el derecho de acceso a los archivos públicos (art. 12 LAIPTBG).

De los contenidos de la ley, que se enuncian en su título, el derecho de acceso a la información pública es la vía más importante de materialización del principio de transparencia, por su alto potencial transformador del ordenamiento y de la práctica administrativa en orden a visibilizar la actuación pública, lo que constituye una exigencia de primer orden en un Estado democrático.

Pero es evidente que este derecho constitucional que desarrolla la Ley de Transparencia no eclipsa en modo alguno su naturaleza "fundamental", reconocida en varias declaraciones internacionales y por una asentada jurisprudencia del $\mathrm{TEDH}^{47}$. En nuestro ordenamiento, aun cuando no está expresamente previsto en la CE, su íntima conexión con otros derechos fundamentales como son los derechos de participación en los asuntos públicos (art. $23 \mathrm{CE}$ ) y las libertades de expresión, pero, sobre todo, de información (art. $20 \mathrm{CE}$ ), respecto de los cuales el derecho de acceso es un presupuesto lógico inescindible. Esta innegable e íntima conexión, como señala F. Rey, podrían haber servido al legislador, para declarar (que no crear) un "nuevo" derecho fundamental ${ }^{48}$.

En relación con la libertad de información, es pacífico que la libertad de acceso a las fuentes, es un presupuesto indispensable que compromete la existencia misma del derecho a la información, en su doble vertiente de dar y recibir

\footnotetext{
${ }^{47}$ Aunque el CEDH no menciona expresamente el derecho de acceso a la información pública, sí lo reconoce como "instrumental" de otros derechos protegidos por el convenio como la libertad de expresión e información. De esta forma, se entiende que los derechos del art. 10 CEDH pueden verse menoscabados por la negativa a la solicitud de información pública no solo a periodistas e informadores, sino por ONG, investigadores o particulares (SSTEDH Társaság a Szabadságjogokért c. Hungría, 14 de abril de 2009, Kenedi c. Hungary, 26 de mayo de 2009, Youth Initiative for Human Rights c. Serbia, 25 de junio de 2013, que culminan en, STEDH Magyar Helsinki Bizottság v. Hungary, 8 de noviembre de 2016).

${ }^{48}$ Rey Martínez, F., "Quod omnes tangit ab omnibus cognitum esse debet: el derecho de acceso a la información pública como derecho fundamental", Revista Jurídica de Castilla y León, n³3, Monográfico sobre transparencia, A. Moretón Toquero coord., 2014.
} 
información, pero también, la veracidad. Creo que esto es así, sobre todo, cuando la información que se suministra es una información que la fuente posee en monopolio, como ocurre con la información pública, donde la propia Administración es la fuente.

Esta "fundamentalidad" del derecho de acceso, que es presupuesto ineludible de la libertad de información y medio de control de la actividad pública, emerge claramente en la situación de estado de alarma, y por ello habría merecido un tratamiento diferenciado de otros procedimientos administrativos como límite infranqueable a la suspensión.

Aun cuando la configuración del derecho de acceso como un derecho público subjetivo en la Ley de transparencia pudiera empañar su naturaleza fundamental, la suspensión de los plazos se compadece mal con una cabal consideración de su amplitud y la consiguiente interpretación estricta de los límites de este derecho que aparecen tasados en la ley (art. 14 LTAIPBG) así como de las causas de inadmisión de las solicitudes de información (art. 18 LTAIPBG).

Esta interpretación amplia del derecho de acceso encuentra acogida en la jurisprudencia (por todas, STS 1547/2017, de 16 de octubre) que solo considera aceptables las limitaciones que resulten justificadas y proporcionadas a su objeto y finalidad de protección, y que atiendan a las circunstancias del caso concreto, especialmente a la concurrencia de un interés público o privado superior que justifique el acceso (art. 14.2 LTAIPBG). Así pues, "la posibilidad de limitar el derecho de acceso a la información no constituye una potestad discrecional de la Administración o entidad a la que se solicita información, pues aquel es un derecho reconocido de forma amplia y que sólo puede ser limitado en los casos y en los términos previstos en la Ley" (Mestre Delgado).

Como señala M. A. Blanes "suspendemos el derecho de acceso a la información pública durante el estado de alarma, precisamente cuando más falta hace, en lugar de potenciarlo y facilitar el rápido acceso a la misma por parte de los periodistas y medios de comunicación que conforman la opinión pública libre e informada". En un contexto de incertidumbre generalizada, la necesidad de 
información solvente en materia tan sensible como la sanitaria ${ }^{49}$ (aunque no solo), la propia excepcionalidad del estado de alarma (muy prolongada en el tiempo) con el ineludible control de la gestión pública y rendición de cuentas, y la no menos importante misión de hacer frente a la proliferación de noticias falsas, entre otras, parece que eran razones suficientes para, conforme al principio de proporcionalidad y conveniencia, avalar la excepción a la suspensión de los procedimientos de solicitud de información pública o, al menos, haber reducido la intensidad de la medida limitadora en el ámbito temporal o dando prioridad en la respuesta ${ }^{50}$. Una posibilidad que el repetido Real Decreto 465/2020, de 17 de marzo parecía abrir dejándolo en manos de las entidades del sector público ${ }^{51}$ pero que, en la práctica, se ha traducido en la suspensión de la tramitación de las solicitudes (y recursos) de acceso a la información y, sobre todo, en una debilitación de su propia función, pues no se oculta que el retardo excesivo (indebido) en la respuesta, aun cuando finalmente esta se produzca, devalúa irremediablemente el valor de la información solicitada, lo mismo que su operatividad práctica. En definitiva, una gran ocasión perdida para haber adoptado una decisión también constitucional que, afianzando el carácter fundamental del derecho de acceso, habría sido desde luego mucho más respetuosa con la libertad de información.

Aun cuando son los medios de comunicación y asociaciones profesionales quienes primero alertaron de las limitaciones de acceso a la información y la restricción de la transparencia administrativa, no está de más recordar que esta es una cuestión que afecta no solo a los profesionales de la información, sino a

\footnotetext{
49 La UE ha llevado a cabo una estrategia de lucha contra la desinformación en esta materia ofreciendo fuentes solventes. Accesible en: https://ec.europa.eu/info/live-work-traveleu/health/coronavirus-response/fighting-disinformation es

${ }^{50}$ Desde el punto de vista material, y partiendo de que el confinamiento que se deriva del estado de alarma hace incompatible el normal desarrollo del trabajo vinculado a dar respuesta a una solicitud de información, Esperanza Zambrano apuntó como "deseable una identificación de las solicitudes vinculadas a esta crisis y darles prioridad en la respuesta". Vid. ZAMBRANO, E.: "Crisis sanitaria, no crisis en transparencia".

Accesible en: https://investigacionapi.com/portada/2020/03/30/crisis-sanitaria-no-crisis-entransparencia/

Una solución de tramitación preferente se ha adoptado en el ámbito procesal para la tramitación de determinados procedimientos judiciales en el orden social, civil y contencioso-administrativo directamente surgidos de la crisis sanitaria por la Covid-19, así como de aquellos que se han visto afectados por las consecuencias de la misma, en la Ley $3 / 2020$, de 18 de septiembre, de medidas procesales y organizativas para hacer frente al COVID-19 en el ámbito de la Administración de Justicia.( BOE núm. 250, Sábado 19 de septiembre de 2020).

51 En este mismo sentido, Blanes Climent, M.A.: "Comentarios a la nota del portal de transparencia", óp. cit.
} 
fundación

Manuiel Giménez Abad

todos los ciudadanos en general, como destinatarios, pero también, titulares del derecho a la información en su doble vertiente (art. $20 \mathrm{CE}$ ) y del derecho de acceso a los archivos y registros públicos (art. 105 b CE). 